\title{
Assessment of models for anaerobic biodegradation of a model bioplastic: Poly(hydroxybutyrate-co-hydroxyvalerate)
}

\section{Authors: Cecily A. Ryan, Sarah L. Billington, Craig S. Criddle}

NOTICE: this is the author's version of a work that was accepted for publication in Bioresource Technology. Changes resulting from the publishing process, such as peer review, editing, corrections, structural formatting, and other quality control mechanisms may not be reflected in this document. Changes may have been made to this work since it was submitted for publication. A definitive version was subsequently published in Bioresource Technology, [VOL\# 27, March 2017)] DOI\# 10.1016/j.biortech.2016.11.119

Ryan, Cecily A., Sarah L. Billington, and Craig S. Criddle. "Assessment of models for anaerobic biodegradation of a model bioplastic: Poly(hydroxybutyrate-co-hydroxyvalerate)." Bioresource Technology 227 (March 2017): 205-213. DOI: 10.1016/j.biortech.2016.11.119.

Made available through Montana State University's $\underline{\text { ScholarWorks }}$ scholarworks. montana.edu 


\title{
Assessment of models for anaerobic biodegradation of a model bioplastic: Poly(hydroxybutyrate-co-hydroxyvalerate)
}

\author{
Cecily A. Ryan*, Sarah L. Billington, Craig S. Criddle \\ Department of Civil and Environmental Engineering, Stanford University, 473 Via Ortega, Stanford, CA 94305, United States
}

\begin{abstract}
A B S T R A C T
Kinetic models of anaerobic digestion (AD) are widely applied to soluble and particulate substrates, but have not been systematically evaluated for bioplastics. Here, five models are evaluated to determine their suitability for modeling of anaerobic biodegradation of the bioplastic poly(hydroxybutyrate-cohydroxyvalerate) (PHBV): (1) first-order kinetics with and without a lag phase, (2) two-step first-order, (3) Monod (4) Contois, and (5) Gompertz. Three models that couple biomass growth with substrate hydrolysis (Monod, Contois, and Gompertz) gave the best overall fits for the data $\left(R^{2}>0.98\right.$ ), with reasonable estimates of ultimate $\mathrm{CH}_{4}$ production. The particle size limits of these models were then evaluated. Below a particle size of $0.8 \mathrm{~mm}$, rates of hydrolysis and acetogenesis exceeded rates of methanogenesis with accumulation of intermediates leading to a temporary inhibition of $\mathrm{CH}_{4}$ production. Based on model fit and simplicity, the Gompertz model is recommended for applications in which particle size is greater than $0.8 \mathrm{~mm}$.
\end{abstract}

\section{Introduction}

Biodegradable plastics offer a more environmentally sustainable alternative to traditional plastics for a variety of applications, but management of these materials at end-of-life is critical for sustainability. Uncontrolled degradation of organic materials in anaerobic environments leads to release of methane $\left(\mathrm{CH}_{4}\right)$ into the atmosphere; by contrast, controlled anaerobic biodegradation via anaerobic digestion (AD) can enable efficient recovery of $\mathrm{CH}_{4}$ for use as a fuel or feedstock. AD has been widely studied for a variety of solid organic wastes (Ge et al., 2016; Vavilin et al., 1996, 2008; Xu et al., 2015), but emerging bioplastics, such as polylactic acid and poly (hydroxyalkanoates) (PHAs), have received little attention. This work addresses this deficiency by evaluating kinetic models previously used for modeling of solid substrate degradation to determine their applicability for modeling of the anaerobic biodegradation of a model bioplastic: Poly(hydroxybutyrate-cohydroxyvalerate) (PHBV), a commercially available PHA with mechanical properties similar to those of polypropylene (Miller et al., 2015; Tsui et al., 2013).

\section{Kinetic models of solid substrate degradation}

Several steps must be considered when modeling the biodegradation of solid substrates, such as bioplastics, including: (1) initial colonization of a surface and biofilm formation, (2) diffusion of enzymes to the surface, (3) hydrolysis, (4) diffusion and degradation of hydrolysis products, (5) conversion of hydrolysis products into intermediates, and (6) conversion of intermediates to $\mathrm{CH}_{4}$ by methanogenic biomass. To develop practical models with a small number of fitting parameters, a rate-limiting step is typically 
Table 1

Expressions used to model bioplastic degradation.

\begin{tabular}{|c|c|c|}
\hline Model & Description & \\
\hline Monod & $\begin{array}{l}\text { Rate Limiting Step } \\
\text { Lag Time } \\
\text { Assumptions }\end{array}$ & $\begin{array}{l}\boldsymbol{\mu}_{\boldsymbol{m}} \text { : maximum specific growth rate }\left[\mathrm{T}^{1}\right] \\
\boldsymbol{K}_{\boldsymbol{s}} \text { : Monod constant }\left[\mathrm{M}_{\mathrm{S}} \mathrm{L}^{-3}\right] \\
\boldsymbol{X} \text { : biomass concentration }\left[\mathrm{M}_{\mathrm{X}} \mathrm{L}^{-3}\right] \\
\boldsymbol{Y} \text { : biomass yield }\left[\mathrm{M}_{\mathrm{X}} \mathrm{M}_{\mathrm{S}}^{-1}\right] \\
\text { Acetoclastic methanogenesis } \\
\text { Yes } \\
\text { Rapid hydrolysis, rate determined by microbial growth controlling methanogenesis (Vavilin } \\
\text { et al., 2008) }\end{array}$ \\
\hline First-Order & $\begin{array}{l}\text { Parameters }^{\dagger} \\
\text { Rate Limiting Step } \\
\text { Lag Time } \\
\text { Assumptions }\end{array}$ & $\begin{array}{l}\boldsymbol{k} \text { : maximum hydrolysis rate constant }\left[\mathrm{T}^{-1}\right] \\
\text { Substrate hydrolysis } \\
\text { No } \\
\text { Rate and substrate concentration are proportional, rate limited by surface availability of the } \\
\text { substrate (Vavilin et al., 2008) }\end{array}$ \\
\hline $\begin{array}{l}\text { First-Order } \\
\text { With Lag }\end{array}$ & $\begin{array}{l}\text { Parameters } \\
\text { Rate Limiting Step } \\
\text { Lag Time } \\
\text { Assumptions }\end{array}$ & $\begin{array}{l}\boldsymbol{k} \text { : maximum hydrolysis rate constant }\left[\mathrm{T}^{-1}\right] \\
\lambda \text { : Initial lag time to substrate hydrolysis }[\mathrm{T}] \\
\text { Substrate hydrolysis } \\
\text { Yes } \\
\text { After initial lag, reaction is first-order }\end{array}$ \\
\hline $\begin{array}{l}\text { Two-Step } \\
\text { With Lag }\end{array}$ & $\begin{array}{l}\text { Parameters }^{\dagger} \\
\text { Rate Limiting Step } \\
\text { Lag Time } \\
\text { Assumptions }\end{array}$ & $\begin{array}{l}\boldsymbol{k}_{\boldsymbol{H}} \text { : first-order kinetics constant of substrate degradation into VFAs }\left[\mathrm{T}^{-1}\right] \text { (first step) } \\
\boldsymbol{k}_{\boldsymbol{V} \boldsymbol{F}} \text { : first-order kinetics constant of VFA degradation into } \mathrm{CH}_{4}\left[\mathrm{~T}^{-1}\right] \text { (second step) } \\
\text { Two potentially rate determining steps: hydrolysis to VFAs and coversion of VFAs to } \mathrm{CH}_{4} \\
\text { Yes } \\
\text { Two first order reactions describing hydrolysis/acetogenesis and acetoclastic methanogenesis } \\
\text { (Brulé et al., 2014) }\end{array}$ \\
\hline Contois & $\begin{array}{l}\text { Rate Limiting Step } \\
\text { Lag Time } \\
\text { Assumptions }\end{array}$ & $\begin{array}{l}\rho_{\mathbf{m}} \mathbf{H} \text { : maximum hydrolysis rate }\left[\mathrm{M}_{\mathrm{S}} \mathrm{M}_{\mathrm{X}}^{-1} \mathrm{~T}^{-1}\right] \\
\boldsymbol{K}_{\mathbf{C}} \text { : Contois constant }\left[\mathrm{M}_{\mathrm{S}} \mathrm{M}_{\mathrm{X}}^{-1}\right] \\
\boldsymbol{X}_{\boldsymbol{H}} \text { : hydrolytic (acidogentic) biomass concentration }\left[\mathrm{M}_{\mathrm{X}} \mathrm{L}^{-3}\right] \\
\boldsymbol{Y}_{\boldsymbol{H}} \text { : hydrolytic biomass yield }\left[\mathrm{M}_{\mathrm{X}} \mathrm{M}_{\mathrm{S}}^{-1}\right] \\
\text { Substrate hydrolysis coupled to growth of hydrolytic biomass } \\
\text { Yes } \\
\text { A single parameter can represent saturation of both substrate and biomass (Vavilin et al., } \\
2008 \text { ) }\end{array}$ \\
\hline Gompertz & $\begin{array}{l}\text { Parameters }^{\dagger} \\
\text { Rate Limiting Step } \\
\text { Lag Time } \\
\text { Assumptions }\end{array}$ & $\begin{array}{l}\boldsymbol{R} \text { : maximum rate of } \mathrm{CH}_{4} \text { production }\left[\mathrm{L}_{\mathrm{CH}_{4}}^{3} \mathrm{M}_{S}^{-1} \mathrm{~T}^{-1}\right] \\
\lambda \text { : lag time to } \mathrm{CH} 4 \text { production }[\mathrm{T}] \\
\text { Microbial growth rate (not explicitly limited by substrate hydrolysis) } \\
\text { Yes } \\
\text { Not constrained by availability of substrate, direct relationship between substrate utilization, } \\
\text { methanogenic biomass growth, and } \mathrm{CH}_{4} \text { production (Zwietering et al., 1990; Lay et al., 1998) }\end{array}$ \\
\hline
\end{tabular}

${ }^{\dagger}$ All models include the parameter $\boldsymbol{P}_{\boldsymbol{m}}$, the maximum conversion of substrate into $\mathrm{CH}_{4}\left[L_{\mathrm{CH}_{4}}^{3} M_{S}^{-1}\right]$.

‡ All models neglect biomass decay and this work assumes that the initial $\mathrm{CH}_{4}$ volume, $P_{0}=0$.

assumed. Table 1 summarizes the key models developed to date, fitting parameters, and key assumptions, including rate-limiting steps (Brulé et al., 2014; Lay et al., 1998; Vavilin et al., 2008; Zwietering et al., 1990). Of particular interest are the Contois model and the Gompertz model. The Contois model couples hydrolysis to growth of the hydrolytic biomass with a single fitting parameter (Vavilin et al., 2008). A recent theoretical derivation indicates that this model can account for colonization, diffusion, and uptake of hydrolysis products (Wang and Li, 2014). The Gompertz model accounts for different stages in the conversion of substrate to $\mathrm{CH}_{4}$ and incorporates a lag time parameter, a maximum rate in the linear region of the $\mathrm{CH}_{4}$ generation curve, and the ultimate capacity of $\mathrm{CH}_{4}$ production (Lay et al., 1998; Zwietering et al., 1990).

An important consideration for all of the models in Table 1 is particle size, the key determinant of specific surface area (SSA). SSA can be estimated from particle size, then substituted for the available substrate, $S$, in the Monod and Contois equations of Table 1 (Kong et al., 2003). The maximum rate of hydrolysis, $\rho_{m H}$, then becomes dependent upon SSA.

Understanding how particle size, and therefore surface area, influences the rate of anaerobic degradation is also important for biomaterials management decisions, such as the desirability of mechanical pretreatment to reduce particle size. Smaller particle size can increase hydrolysis rates and accelerate AD (Kong et al.,
2003; Vavilin et al., 2008; Yeh et al., 2010), but the rate of hydrolysis must balance the rate of uptake of volatile fatty acids (VFAs). If the rate of hydrolysis exceeds the rate of uptake of VFAs, VFAs accumulate and methanogenesis can be inhibited, and the models of Table 1 would no longer apply (Vavilin et al., 2004). Smaller particles with high surface area and high rates of hydrolysis could lead to this condition.

The following sections describe anaerobic PHBV degradation experiments and model fits for $\mathrm{CH}_{4}$ production using the kinetic expressions of Table 1 . The aim of this work is to identify a model that provides insights into the mechanisms of PHBV biodegradation and can be incorporated into design models that simulate and predict PHBV degradation in AD applications.

\section{Materials and methods}

\subsection{Materials}

\subsection{1. $P H B V$ and positive control}

PHBV and Positive Control: The bioplastic substrate used in these experiments was $\mathrm{PHBV}$, a biodegradable aliphatic polyester with the chemical formula: $\left[\mathrm{COCH}_{2} \mathrm{CH}\left(\mathrm{CH}_{3}\right) \mathrm{O}\right]_{\mathrm{m}}\left[\mathrm{COCH}_{2} \mathrm{CH}\left(\mathrm{C}_{2} \mathrm{H}_{5}\right) \mathrm{O}\right]_{\mathrm{n}}$. Fine PHBV powder (ENMAT Y1000) and coarse PHBV pellets (ENMAT Y1000P) were obtained from TianAn Biologic Materials 
Co., People's Republic of China. Injection molded PHBV samples made from the PHBV pellets were fabricated per the process of Srubar et al. (Srubar et al., 2012) and were rectangular prisms, $31.25 \mathrm{~mm} \times 6.2 \mathrm{~mm} \times 2.1 \mathrm{~mm}$ in dimension. In order to investigate the effects of different particle sizes, PHBV pellets were ground in a standard coffee grinder and sieved to obtain 3 lots of ground pellets in particle sizes shown in Fig. 1, Panel (a). Unground PHBV pellets and PHBV powder were used to provide higher and lower particle sizes to the ground samples. The measured density, $\rho$, of bulk PHBV was $1.25 \mathrm{~g} / \mathrm{cm}^{3}$.

Avicel ${ }^{\circledR}$ PH105 microcrystalline cellulose was used as a positive control (ASTM, 2002). The average particle size was $20 \mu \mathrm{m}$, with particle diameters ranging from $5-30 \mu \mathrm{m}$ and a length-to-width aspect ratio of 2-3 (Katdare and Chaubal, 2006).

\subsubsection{Particle characterization}

In order to assess the particle surfaces and diameter of the different samples, the ground PHBV pellets and powder were imaged using optical microscopy with a Nikon SMZ800 Optical Microscope. Images were calibrated with a micrometric graticule (Silicone Test Specimen, EMS, Catalog \# 79502) with $500 \mu \mathrm{m}$ coarse spacing and fine spacing of $10 \mu \mathrm{m}$.

The Brunauer, Emmett and Teller (BET) method was used to determine the SSA of the different particle size fractions using a
Micromeritics ASAP 2020 Surface Area and Porosity Analyzer and nitrogen $\left(\mathrm{N}_{2}\right)$ adsorption. Approximately $2 \mathrm{~g}$ of powdered sample was used for the analysis. Prior to measuring the SSA, samples were degassed at $110^{\circ} \mathrm{C}$ for $12 \mathrm{~h}$, weighed, and then loaded into the BET for analysis. The analysis conditions were for the full isotherm for BET and BJH poresize.

For samples too large for BET analysis, sample dimensions were measured with Mitutoyo Model CD-6"C Calipers for larger sample dimensions (greater than $25 \mathrm{~mm}$ ) and with a Mitutoyo Model 293344 Micrometer for smaller sample dimensions. Three locations along a sample plane were selected for each dimension and averaged to calculate sample surface area and volume.

Fig. 1 shows the surface area of the different particle size fractions (Panel a) and the BET surface area and calculated diameter (Panel b). The solid line in Fig. 1a shows the relationship that would be expected for spherical, non-porous particles of a known density $\left(\rho=1.25 \mathrm{~g} / \mathrm{cm}^{3}\right)$. The measured SSA leads to a smaller particle size than would be expected.

The PHBV particles are not spherical and have additional surface roughness, therefore this deviation from theory can be expected. BET is a surface area measurement inferred from $\mathrm{N}_{2}$ adsorption on the particle surfaces, and is expected to overestimate the surface area $(S A)$ available for enzymatic binding. Despite this limitation, the BET method provides a quantifiable assessment

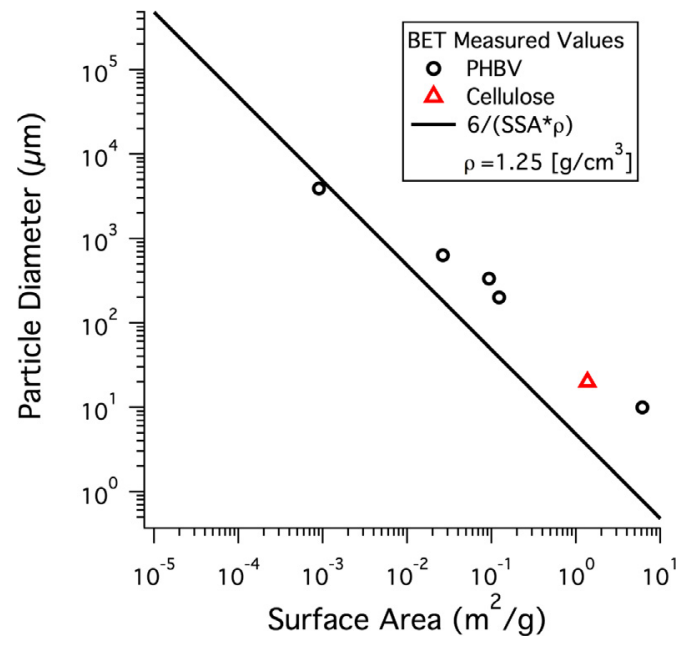

(a)

PHBV particle size and BET surface area and particle diameter

\begin{tabular}{l||cccc}
\hline Sample & $\begin{array}{c}\text { Sieve No. } \\
{[\mathbf{M e s h}]}\end{array}$ & $\begin{array}{c}\text { Particle Size } \\
{[\mu \mathbf{m}]}\end{array}$ & $\begin{array}{c}\text { BET SSA } \\
{\left[\mathbf{m}^{2} / \mathbf{g}\right]}\end{array}$ & $\begin{array}{c}\text { BET Diameter } \\
{[\boldsymbol{\mu m}]}\end{array}$ \\
\hline PHBV: & & & & NA \\
Injection Molded & NA & $6,584^{\dagger},{ }^{*}$ & NA & 5333 \\
Pellets & NA & $3900^{\dagger}$ & 0.0009 & 182 \\
Ground 1 & $-20+40$ & $420-840$ & 0.0264 & 52 \\
Ground 2 & $-40+60$ & $250-420$ & 0.093 & 39 \\
Ground 3 & $-60+100$ & $150-250$ & 1.222 & 0.8 \\
Powder & NA & $10^{\ddagger}$ & 6.1445 & 2.9 \\
Cellulose & NA & $20^{\ddagger}$ & 1.3651 & \\
\hline
\end{tabular}

${ }^{\dagger}$ Measured via caliper.

$\ddagger$ Reported.

* Calculated from rectangular prism, $31.25 \mathrm{~mm} \times 6.2 \mathrm{~mm} \times 2.1 \mathrm{~mm}$.

(b)

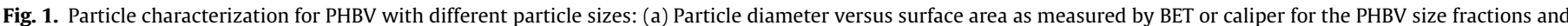

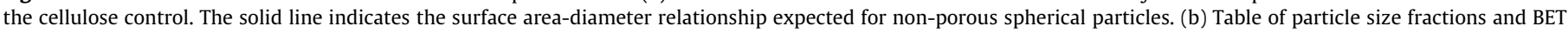
surface area and particle diameter. Particle size is listed from coarsest (pellets) to finest (powder). 
of the SSA of each size fraction that can be used to assess how SA impacts $\mathrm{CH}_{4}$ production rates and lag times.

\subsection{Experimental setup}

Methane production was continuously measured using the AMPTS II from Bioprocess Control. Experiments to assess models for anearobic biodegradation were performed using injection molded bioplastic samples and were tested in a separate experimental group from the samples used to evaluate the dependence of $\mathrm{CH}_{4}$ production on particle size. For each experimental group, negative controls (inoculated media) were run in triplicate. Microcrystalline cellulose (Avicel ${ }^{\circledR}$ PH105) was used as a positive control. The positive control was judged "fully biodegraded" when the $\mathrm{CH}_{4}$ produced was equal to or greater than $80 \%$ of the theoretical $\mathrm{CH}_{4}$ production potential (ThCH4) (Mezzanotte et al., 2005). Stoichiometry was used to calculate the theoretical $\mathrm{CH}_{4}$ production for a known mass of PHBV (Buswell and Mueller, 1952; Ryan, 2016). Briefly, the chemical oxygen demand (COD) of PHBV and the cellulose control were calculated as $1.69 \mathrm{gCOD} / \mathrm{g}$ for PHBV and $1.19 \mathrm{~g} C O D / g$ for cellulose. COD was then used to calculate the theoretical methane production from PHBV, $672 \mathrm{~mL} / \mathrm{gPHBV}$, which was compared to the measured $\mathrm{CH}_{4}$ production and used to calculate the extent of biodegradation of the PHBV over time. To ensure equal COD loading between the reactors: (1) for model evaluation PHBV was added to each test reactor at $0.5 \mathrm{~g}$, and microcrystalline cellulose (positive control) was added at $0.68 \mathrm{~g}$; (2) for evaluation of surface area effects, $1.17 \mathrm{~g}$ of the different PHBV size fractions was added to each test sample reactor, and $1.7 \mathrm{~g}$ of microcrystalline cellulose to each positive control reactor. These amounts give an inoculum to substrate ratio of (1) 1.1 for model evaluation and (2) 0.5 for particle size evaluation; both values are within a desirable range for optimal $\mathrm{CH}_{4}$ production (Boulanger et al., 2012; Liu et al., 2009). Duplicates were analyzed of each size fraction and the positive control (cellulose).

Each sample was placed in 500-mL media bottles, which were filled with $500 \mathrm{~mL}$ of inoculated anaerobic media, retaining a $100 \mathrm{~mL}$ gas headspace. The bottles were stoppered and the headspace was sparged with $70: 30 \mathrm{~N}_{2} / \mathrm{CO}_{2}$ before and during filling to maintain anaerobic conditions in the sample container. The inoculated anaerobic media was continuously stirred during filling with a magnetic stirrer and gas agitation from being sparged with $\mathrm{N}_{2}$ / $\mathrm{CO}_{2}$. Reactors were filled sequentially; media was pumped continuously with a bellows metering pump (GRI 14251-003). Once filled, the bottles were connected with viton tubing to the Automated Methane Test Setup (AMPTS) gas measuring setup. Bioreactors were maintained at $37^{\circ} \mathrm{C}$ by keeping them submerged in a water bath.

Gas sampling "T's" inline after the reactor headspace and before the carbon dioxide $\left(\mathrm{CO}_{2}\right)$ traps were used to sample the gas composition during degradation using gas chromatography. Gas sampling "T's" were obtained through BioProcess Control via SeaHold LLC. These glass sampling ports were fit with $13 \mathrm{~mm}$ butyl rubber/Teflon stoppers (Kimble Chase, Part No. 73811T-13), sealed with $13 \mathrm{~mm}$ tear-off aluminum crimp seals. $\mathrm{CO}_{2}$ traps were added inline and filled with $3 \mathrm{M}$ sodium hydroxide with a thymolphthalein $\mathrm{pH}$ indicator. $\mathrm{CH}_{4}$ was measured volumetrically in calibrated reservoirs in increments of approximately $10 \mathrm{~mL}$. Data were calibrated, normalized, and corrected for negative control gas volume using Matlab. Reactors were enabled for overhead mixing with a stir speed of $50 \mathrm{rpm}$ and $4 \mathrm{~h}$ mixing cycles: $30 \mathrm{~min}$ of mixing followed by $330 \mathrm{~min}$ of quiescence. These parameters were selected based on prior work indicating that aggressive mixing may inhibit microbial adhesion on the bioplastic substrates (Gartiser et al., 1998; Morse, 2010).
The gas compositions of the reactor headspaces were measured at 3 and 7 days, then every week until the 4th week, at which time $\mathrm{CH}_{4}$ production had slowed. The final reading was obtained at 6 weeks, after the $\mathrm{CH}_{4}$ production had plateaued. The reactor effluent, $2 \mathrm{~mL}$, was collected twice during the period of active degradation (while mixing, at 1.5 and 3 weeks) as well as at the beginning and end of each experiment and measured for $\mathrm{pH}$. Mineral media $(2 \mathrm{~mL})$ was added to each reactor after sampling to prevent errors in gas production measurement due to liquid volume.

After $\mathrm{CH}_{4}$ production from the samples used for model evaluation had plateaued, new PHBV samples and positive controls were added to their respective bioreactors to evaluate any changes that might occur in the biodegradation of the bioplastic due to microbial adaptation to the substrate. All other experimental conditions were kept the same. The Gompertz model was used to compare the impact of substrate acclimation to as-collected inoculum.

\subsection{Anaerobic media and inoculum}

The anaerobic media used for these experiments was based primarily on standard solutions as described in ASTM D5210-92 (ASTM, 2007; Owen et al., 1979), with modifications to concentrations based on other studies (Kenealy and Zeikus, 1981; Shelton and Tiedje, 1984; Wu et al., 1991). The following 4 concentrated stock solutions were used: (S1) resazurin, $0.5 \mathrm{~g} / \mathrm{L}$; (S2) $\mathrm{KH}_{2} \mathrm{PO}_{4}$, $69 \mathrm{~g} / \mathrm{L}, \mathrm{K}_{2} \mathrm{HPO}_{4}, 88 \mathrm{~g} / \mathrm{L}, \mathrm{NH}_{4} \mathrm{Cl}, 100 \mathrm{~g} / \mathrm{L}$; (S3) $\mathrm{MgCl}_{2} \cdot 6 \mathrm{H}_{2} \mathrm{O}, 60 \mathrm{~g} / \mathrm{L}$ $\mathrm{CaCl}_{2} \cdot 2 \mathrm{H}_{2} \mathrm{O}, 45 \mathrm{~g} / \mathrm{L}, \mathrm{FeCl}_{2}, 12 \mathrm{~g} / \mathrm{L}, \mathrm{MnCl}_{2} \cdot 4 \mathrm{H}_{2} \mathrm{O}, 400 \mathrm{mg} / \mathrm{L}, \mathrm{CoCl}_{2} \cdot 6 \mathrm{H}_{2^{-}}$ $\mathrm{O}, 400 \mathrm{mg} / \mathrm{L}, \mathrm{NiCl}_{2} \cdot 6 \mathrm{H}_{2} \mathrm{O}, 50 \mathrm{mg} / \mathrm{L}, \mathrm{CuCl}_{2}, 50 \mathrm{mg} / \mathrm{L}, \mathrm{ZnSO}_{4} \cdot 7 \mathrm{H}_{2} \mathrm{O}$, $105 \mathrm{mg} / \mathrm{L}, \mathrm{H}_{3} \mathrm{BO} 3,50 \mathrm{mg} / \mathrm{L}, \quad \mathrm{Na}_{2} \mathrm{MoO}_{4} \cdot 2 \mathrm{H}_{2} \mathrm{O}, 50 \mathrm{mg} / \mathrm{L}, \mathrm{Na}_{2} \mathrm{SeO}_{3}$, $10 \mathrm{mg} / \mathrm{L}$; and (S4) $\mathrm{Na}_{2} \mathrm{~S} \cdot 9 \mathrm{H}_{2} \mathrm{O} 50 \mathrm{~g} / \mathrm{L}$. These 4 stock solutions were used in the same proportions as in ASTM D5210 to make the media, following the preparation instructions included in the standard. Bicarbonate $\left(\mathrm{NaHCO}_{3}\right)$ was added to give a final concentration of $50 \mathrm{mM}$ in the media. The anaerobic media was continuously stirred and sparged with $\mathrm{N}_{2} / \mathrm{CO}_{2} 70: 30$ (Praxair certified standard, NI CD30C-K) during the addition of the inoculum to maintain anaerobic conditions. Anaerobic digester sludge was added as an inoculum to the anaerobic mineral media as $10 \mathrm{vol} . \%$ of the total volume.

Anaerobic sludge from digesters treating municipal waste water was selected as the inoculum for these experiments based on existing standards and prior results indicating that it would provide a reliable anaerobic environment to evaluate PHBV degradation (ASTM, 2007; Morse, 2010; Ryan, 2016). Anaerobic inocula were collected from the anaerobic digesters at the San Jose Waste Water Treatment Plant in $4 \mathrm{~L}$ sample containers. These samples were stored in the dark at $37^{\circ} \mathrm{C}$ for two weeks prior to initiating experiments in order to reduce background activity from the sludge. Prior to testing, the sludge was screened through a $1 \mathrm{~mm}$ mesh sieve followed by a single layer of cheese cloth in order to reduce grit and large solids that may have interfered with the experiment. This step was performed immediately before adding the inoculum to the anaerobic media. Anaerobic digester sludge and inoculated media were characterized for COD, $\mathrm{pH}$, suspended solids (SS), volatile solids (VS), and alkalinity in accordance with standard methods (American Public Health Association et al., 1998). The values for both sets of experiments are given in Table 2 .

\subsection{Biogas composition}

Samples analyzed for biogas composition were collected using a $1 \mathrm{~mL}$ gas tight syringe (VICI, Pressure Lok ${ }^{\circledR}$ Series A-2 syringe, Product No. 050033) with a sideport gas sampling needle (VICI, Product No. 943052). $\mathrm{CH}_{4}, \mathrm{CO}_{2}$ and $\mathrm{N}_{2}$ were measured using gas chromatography on a Gow-Mac 580 Series gas chromatograph equipped with a thermal conductivity detector (TCD). The gasses 
Table 2

Characteristics of anaerobic digester sludge inoculum and inoculated media for kinetic evaluation of models and surface area experiments.

\begin{tabular}{|c|c|c|c|c|c|}
\hline \multirow[t]{2}{*}{ Property } & \multicolumn{2}{|c|}{ Kinetic models } & \multicolumn{2}{|l|}{ Surface area } & \\
\hline & Sludge & Media $^{\dagger}$ & Sludge & Media & \\
\hline $\mathrm{pH}$ & 7.56 & 7.51 & 7.68 & 7.52 & \\
\hline Alkalinity & $4,100 \pm 110$ & - & $4,400 \pm 110$ & - & $m g \mathrm{CaCO}_{3} / \mathrm{L}$ \\
\hline COD (Total) & $13,470 \pm 265$ & $3,800 \pm 190$ & $17,000 \pm 250$ & $1,800 \pm 100$ & $\mathrm{mg} C O D / L$ \\
\hline COD (Solids) & $1.4 \pm 0.1$ & - & - & - & g COD/g VSS \\
\hline SS & $16.8 \pm 0.2$ & $2.0 \pm 0.3$ & $5.6 \pm 0.2$ & $1.8 \pm 0.2$ & $g S S / L$ \\
\hline VS & $11.4 \pm 0.1$ & $1.1 \pm 0.2$ & $3.8 \pm 0.1$ & $1.1 \pm 0.2$ & $g V S / L$ \\
\hline
\end{tabular}

Media is inoculated with 10 vol\% anaerobic digester sludge.

‡ Alkalinity samples were titrated to pH 4.5 (American Public Health Association et al., 1998) and measured without biosolid removal.

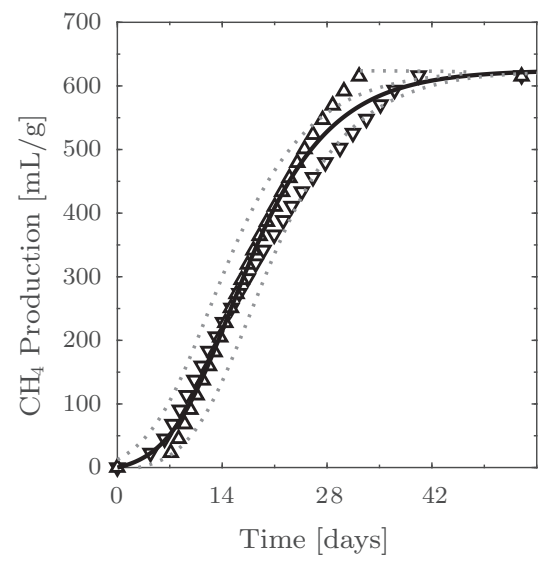

(a) Monod \& Contois

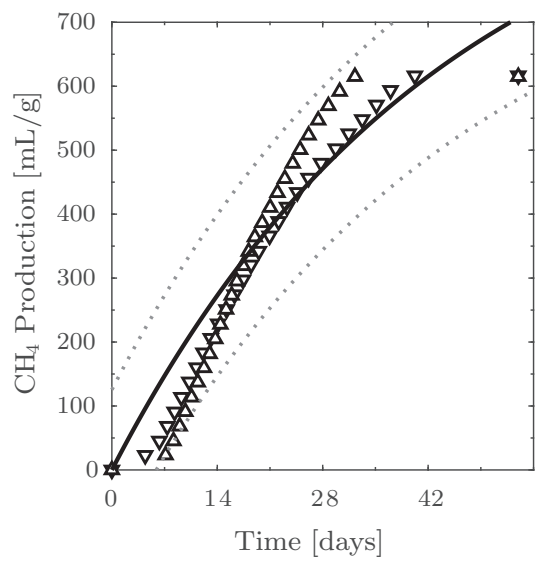

(b) First-Order

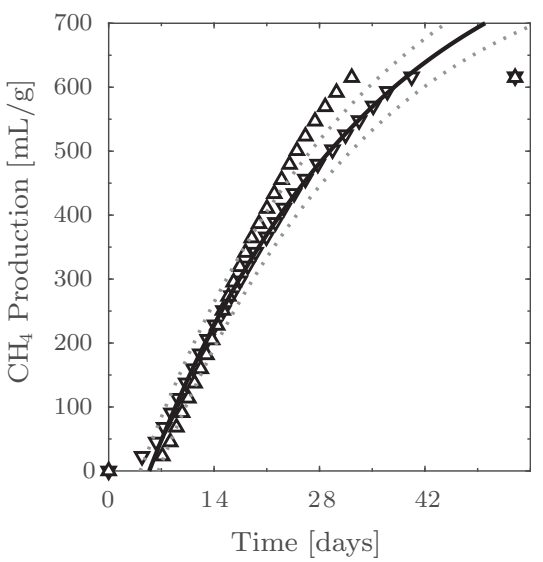

(c) First-Order with Lag

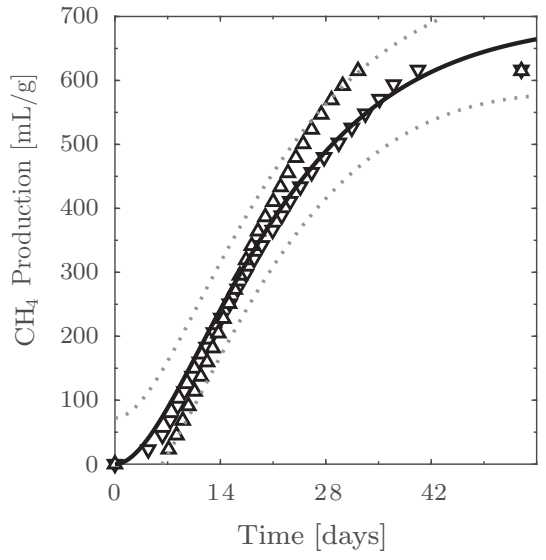

(d) Two-Step

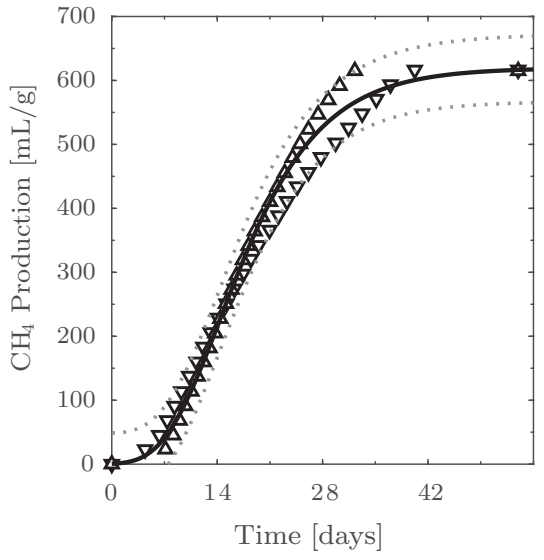

(e) Gompertz

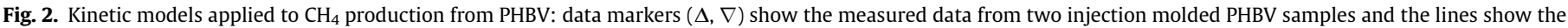
model fit $(-)$ and 95\% prediction bands $(.$.$) for each data set.$

were separated at $45^{\circ} \mathrm{C}$ on a $8^{\prime} \times 1 / 8^{\prime \prime}$ HayeSep Q, 80/100 mesh micropacked column. (He) was used as a carrier gas at a flow rate of $30 \mathrm{~mL} / \mathrm{min}$. The temperature of the injector and detector was kept at $120^{\circ} \mathrm{C}$. The volume collected of all samples and standards was $0.6 \mathrm{~mL}$. Prior to injection, the gas in the syringe was compressed to the $0.5 \mathrm{~mL}$ injection volume, rapidly equilibrated with atmospheric pressure by toggling the valve on the syringe. The sample was then immediately injected into the gas chromatography (GC) sampling port. The standard run time was $4 \mathrm{~min}$. Details on calibration and method development are as described by Ryan (2016).

\subsection{Evaluation of kinetic models}

Matlab 2015b was first used to fit $\mathrm{CH}_{4}$ production from negative control samples. This fit was used to generate a lookup table to subtract out the background $\mathrm{CH}_{4}$ generated by the inoculum from positive control and sample data.

The kinetic models of Table 1 were then fit to $\mathrm{CH}_{4}$ gas production data pooled from two injection molded PHBV samples using the Curve Fitting application in Matlab 2015b, with non linear least squares and the Trust-Region algorithm. Upper and lower 95\% confidence and prediction intervals and goodness of fit $\left(R^{2}\right)$ were cal- 
culated for all fit parameters. Matlab was also used to solve the system of linear equations and extract the kinetic parameters from the fits for the Monod and Contois models. The criteria used to evaluate the models were: (1) ability to accurately predict ultimate $\mathrm{CH}_{4}$ production $\left(P_{m}\right),(2)$ overall goodness of fit $\left(R^{2}\right)$, (3) the $95 \%$ confidence interval of the fit parameters, and (4) the ability to accurately describe the $\mathrm{CH}_{4}$ production over time.

The following experimental parameters were used for model evaluation and $\mathrm{CH}_{4}$ production calculations: (1) $S_{0}=1.58$ g COD/L for PHBV, (2) PHBV was measured to be greater than $99 \%$ volatile solids (for $\mathrm{CH}_{4}$ production calculations), (3) postsieved, filtered volatile solids were assumed to be biosolids such that $X_{0}=1.05 \mathrm{~g} \mathrm{VS} / L$ (Bullock et al., 1996) (used for the Contois model), and (4) the theoretical value for $P_{m}$ (PHBV) at $37^{\circ} \mathrm{C}$ is $672 \mathrm{~mL} \mathrm{CH}_{4} / \mathrm{g}$ VS.

IgorPro 6.37 was used to analyze the maximum rate and lag time in the surface area experiments. Rate and lag time were calculated from the derivative of $\mathrm{CH}_{4}$ production with time, as the peak value of the derivative (maximum rate) and the time to initiation of $\mathrm{CH}_{4}$ production. These values were used to model how surface area affects degradation using non-linear regression in Igor Pro. This model generated maximum $\mathrm{CH}_{4}$ production rate, $R$, and lag time for $\mathrm{CH}_{4}$ production, $\lambda$, which were then used as inputs into the Gompertz model.

\section{Results and discussion}

\subsection{Kinetic models of PHBV biodegradation}

Fig. 2 shows the different models applied to $\mathrm{CH}_{4}$ gas production data from the two rectangular prism samples of injection-molded PHBV. Table 3 summarizes the resultant fit parameters and goodness of fit for the various models. While all fit $R^{2}$ values were greater than 0.89 , not all models were able to accurately capture the features of the $\mathrm{CH}_{4}$ production curves. In particular, the firstorder overestimated the ultimate $\mathrm{CH}_{4}$ produced, and overpredicted initial $\mathrm{CH}_{4}$ production. Adding the lag time factor into the first-order equation significantly improved the model fit for the initial $\mathrm{CH}_{4}$ production and rate constant, but still overestimated ultimate $\mathrm{CH}_{4}$ yield.

The Monod, Contois, two-step first-order, and Gompertz models provided good fits for $\mathrm{CH}_{4}$ production. The Monod, Contois, and Gompertz models provided the best fit for the data as determined by comparing $R^{2}$, the confidence intervals of the fit parameters, and the ability to predict ultimate $\mathrm{CH}_{4}$ production. The convergence of both the Monod-Contois fit and the two-step fit were sensitive to initialization values. The two-step model yielded wider 95\% confidence intervals and prediction bands than the Monod, Contois, and Gompertz models and slightly over predicted $\mathrm{CH}_{4}$ production. Overall, the two-step model was less accurate in capturing the $\mathrm{CH}_{4}$ production over time than the Monod, Contois, and Gompertz models. However, it is notable that the fit values for $k_{H}$ and $k_{V F A}$ in the two-step are very similar. If a microbial biofilm is limiting diffusion of hydrolysis products to methanogenic biomass, the hydrolysis-limiting assumption often made for particulate substrates may not be accurately addressing the complexity of this system.

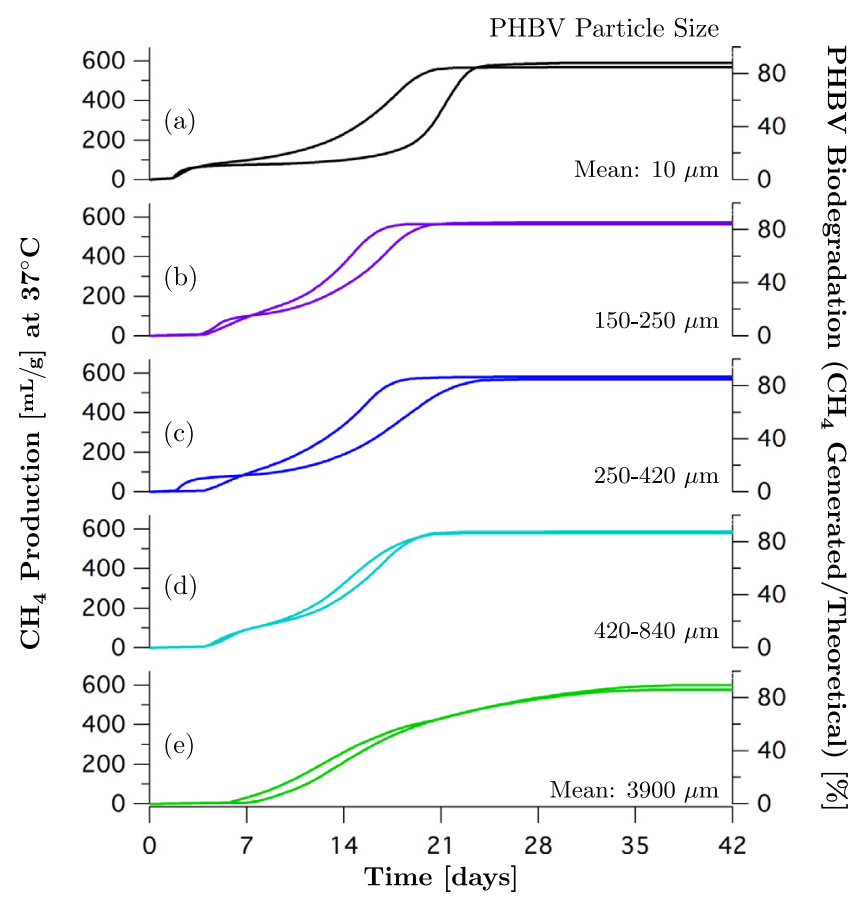

Fig. 3. $\mathrm{CH}_{4}$ production and extent of biodegradation of PHBV with different particle sizes over time. Temporary inhibition of methanogenesis for particle sizes less than $840 \mu \mathrm{m}$ is attributed to the accumulation of VFAs caused by the rate of hydrolysis and acetogenesis exceeding that of methanogenesis. As particle size decreases from bottom (e) PHBV pellets to top (a) PHBV powder, this effect becomes more pronounced.

Table 3

Model fit parameters for anaerobic biodegradation of PHBV.

\begin{tabular}{|c|c|c|c|c|c|}
\hline Model & & & Parameter $^{\dagger}$ & $R^{2}$ Fit & \\
\hline Monod & $\begin{array}{l}\boldsymbol{P}_{\boldsymbol{m}}\left[\frac{m L C H_{4}}{g P H B V}\right] \\
625 \pm 10\end{array}$ & $\begin{array}{l}\boldsymbol{\mu}_{\boldsymbol{m}}\left[\frac{1}{d a y}\right] \\
0.2 \pm 0.1 \\
\boldsymbol{k}\left[\frac{1}{d a y}\right]\end{array}$ & $\begin{array}{l}\boldsymbol{K}_{\boldsymbol{s}}\left[\frac{g C O D}{L}\right] \\
2.9 \pm 0.1\end{array}$ & $\begin{array}{l}\boldsymbol{X}_{0} / \boldsymbol{Y}\left[\frac{g C O D}{L}\right] \\
0.02 \pm 0.03\end{array}$ & 0.986 \\
\hline First-Order & $1000 \pm 400$ & $\begin{array}{l}0.023 \pm 0.002 \\
\boldsymbol{k}\left[\frac{1}{d a y}\right]\end{array}$ & $\lambda[$ days $]$ & & 0.893 \\
\hline First-Order with lag & $897 \pm 60$ & $\begin{array}{l}0.034 \pm 0.031 \\
\boldsymbol{k}_{\boldsymbol{H}}\left[\frac{1}{d a y}\right]\end{array}$ & $\begin{array}{l}5.4 \pm 0.4 \\
\boldsymbol{k}_{\text {VFA }}\left[\frac{1}{d a y}\right]\end{array}$ & & 0.992 \\
\hline Two-Step & $695 \pm 110$ & $\begin{array}{l}0.088 \pm 4.4 \\
\boldsymbol{\rho}_{\boldsymbol{m H}}\left[\frac{g C O D}{g V S \cdot d a y}\right]\end{array}$ & $\begin{array}{l}0.087 \pm 4.4 \\
\boldsymbol{K}_{\boldsymbol{C}}\left[\frac{g C O D}{g V S}\right]\end{array}$ & $\boldsymbol{X}_{\boldsymbol{O H}} / \boldsymbol{Y}_{\boldsymbol{H}}\left[\frac{g C O D}{L}\right]$ & 0.966 \\
\hline Contois & $625 \pm 10$ & $\begin{array}{l}0.02 \pm 0.01 \\
\boldsymbol{R}\left[\frac{m L C H 4}{g P H B V \cdot d a y}\right]\end{array}$ & $\begin{array}{l}0.02 \pm 0.001 \\
\lambda[\text { days }]\end{array}$ & $0.02 \pm 0.01$ & 0.986 \\
\hline Gompertz & $630 \pm 20$ & $28 \pm 1.5$ & $6.4 \pm 0.5$ & & 0.987 \\
\hline
\end{tabular}

$S_{0}=1.58 \mathrm{gCOD} / \mathrm{L}, 1 \mathrm{gPHBV} \approx 1 \mathrm{gVS}, \mathrm{X}_{0}=1.05 \mathrm{gVS} / \mathrm{L}$. At $37^{\circ} \mathrm{C}$ if $100 \%$ of the PHBV is converted to $\mathrm{CH}_{4}, P_{m .100 \%}=672 \mathrm{mLCH} / \mathrm{g}_{\mathrm{PHBV}}$.

$\dagger$ Fit from two pooled data sets of $\mathrm{CH}_{4}$ production from injection molded PHBV, $\pm 95 \%$ confidence interval (from model fit and measurement error). 


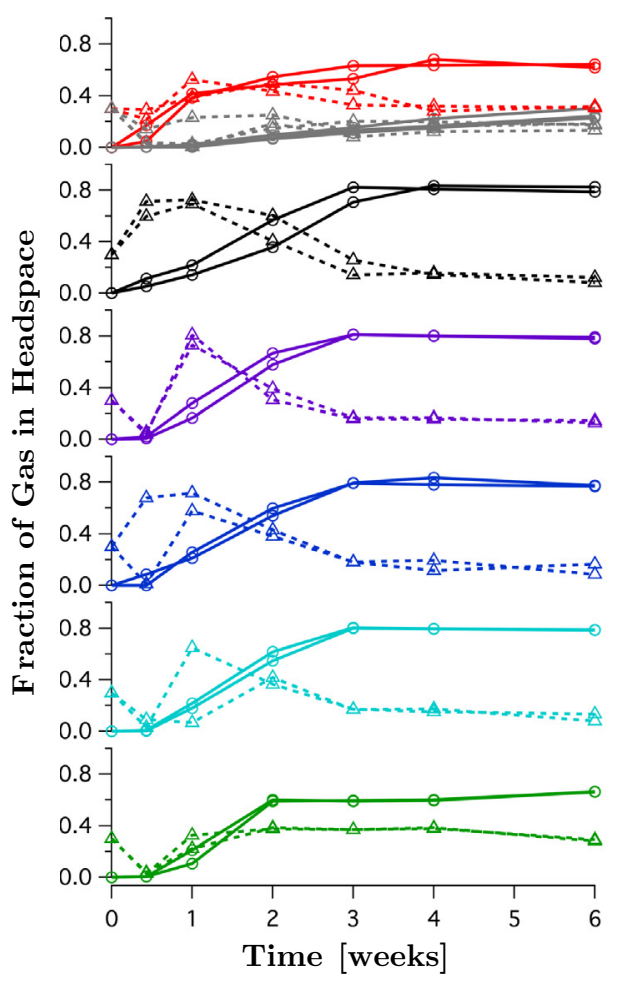

(a)

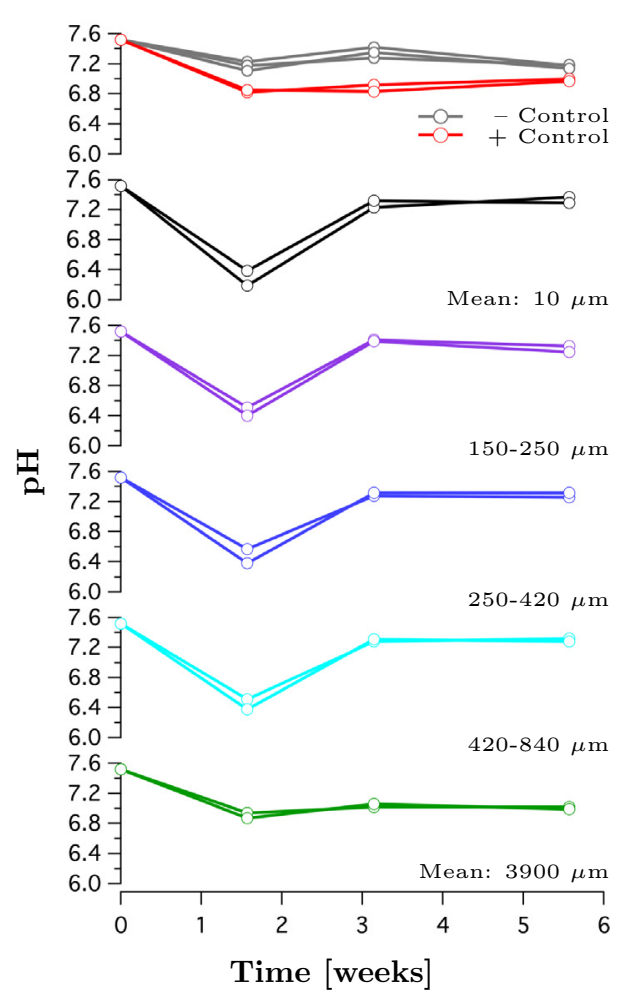

(b)

Legend

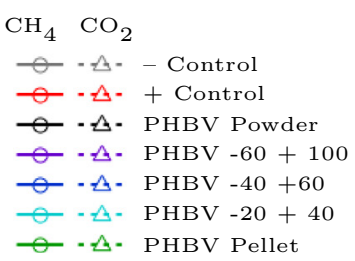

Fig. 4. Biodegradation patterns for differing size particles of PHBV (a) headspace gas composition (b) pH.

Even though the fit form for the Monod and Contois is the same, the additional dependence of the Contois equation on biomass concentration leads to a slightly different interpretation of the model parameters. The derivation of Wang and $\mathrm{Li}$ (Wang and Li, 2014) indicates that the Contois equation reduces to the Monod equation for those cases in which suspended cells have access to the solid substrate surface. Both constants, $K_{S}$ and $K_{C}$, share the physical meaning in that smaller values suggest higher affinities for attached microorganisms to the substrate surface. Thus, the low value obtained for $K_{C}$ (Table 3 ) indicates a high affinity for the bioplastic surface. This hypothesis is supported by scanning electron microscope (SEM) images that showed microbes attached to the bioplastic surface after 10 days of anaerobic degradation and a gentle DI water rinse.

Because both the Monod and Contois models are explicitly dependent on the availability of substrate, rate constants can be defined by the surface area to volume ratios of the initial substrate, and by changes in this ratio over time (Vavilin et al., 2008). This surface sensitivity could be extended to bioplastic and biocomposites of different sizes and dimensions, similar to investigations by Gutierrez-Wing et al. for PHBV films (Gutierrez-Wing et al., 2010). The theoretical applicability of the surface derived model for the Contois equation (Wang and Li, 2014) and the goodness of fit of both the Contois and Gompertz models, makes these two models the most suitable for predicting $\mathrm{AD} \mathrm{CH}_{4}$ production from PHBV.

When the Gompertz model was applied to methane production from PHBV samples in the acclimated reactors, minimal effects due to microbial adaptation to the substrate were observed. The values for the non-acclimated reactors are given in Table 3 as: $P_{m}=630 \pm 20\left[\frac{m L C H_{4}}{g P H B V}\right], R=28 \pm 1.5\left[\frac{m L \mathrm{CH}_{4}}{g P H B V \cdot d a y}\right], \quad$ and $\quad \lambda=6.4 \pm$ 0.5 [days]. The fit for $\mathrm{CH}_{4}$ production from PHBV-adapted bioreactors gave values of $P_{m}=626 \pm 14\left[\frac{m L C H_{4}}{g P P B V}\right], R=28 \pm 2.1\left[\frac{m L C H_{4}}{g P H B V \cdot d a y}\right]$, and $\lambda=5.5 \pm 0.3$ [days]. There was only a minor decrease ( $\sim 0.5-1$ day) in the value of $\lambda$, indicating that the as-collected anaerobic sludge that was used as an inoculum was already well adapted for PHBV degradation. Degradation also initiated rapidly ( $\lambda<1$ day) in the reactors containing the cellulose positive controls with as-collected inoculum, indicating that the inoculum was sufficiently acclimated for cellulosic degradation.

\subsection{Methane production and particle size}

Fig. 3 illustrates biodegradation of the different PHBV particle size fractions in terms of $\mathrm{CH}_{4}$ produced and extent of biodegradation. Ultimate $\mathrm{CH}_{4}$ production is the same for all of the tests 


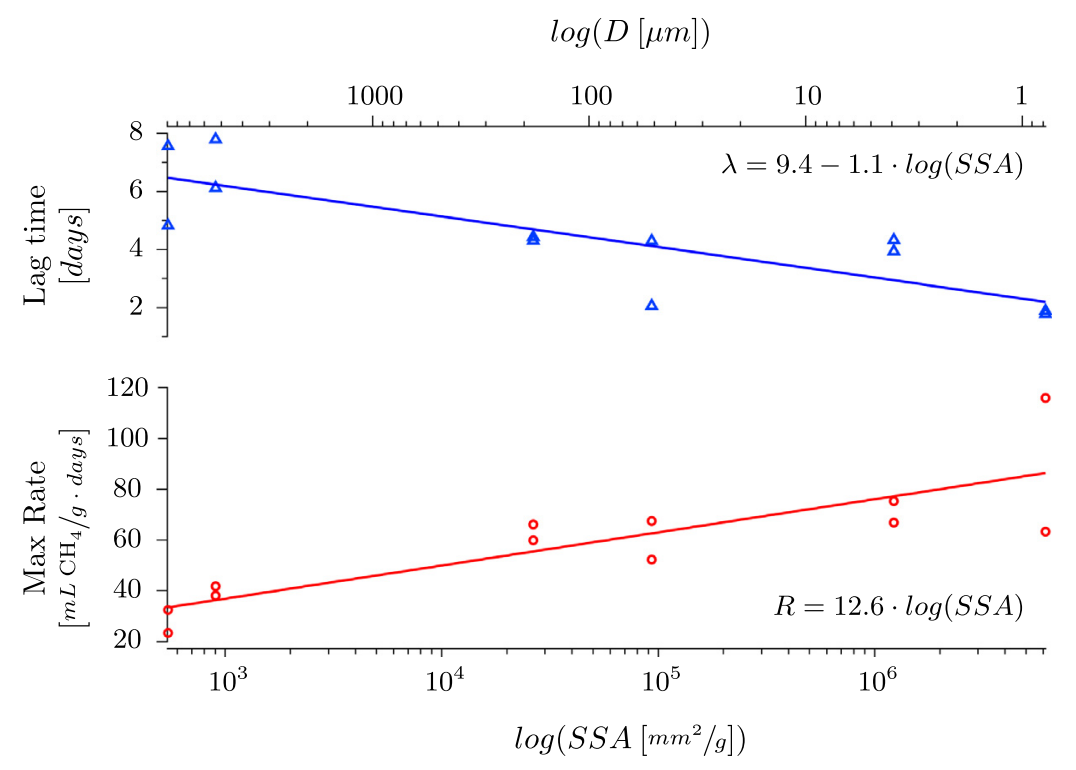

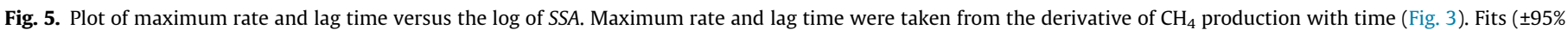
confidence interval) are: (1) $\lambda=A_{1}+M_{1} \cdot \log (S S A)$, where $A_{1}=9.4 \pm 2.5$ and $M_{1}=-1.1 \pm 0.5(2) R=A_{2}+M_{2} \cdot \log (S S A)$, where $A_{2}=0 \pm 13.1$ and $M_{2}=12.6 \pm 2.7$.

( $580 \mathrm{~mL} / \mathrm{g} \pm 12 \mathrm{~mL} / \mathrm{g})$ corresponding to a biodegradability of $86 \pm 2 \%$, but there is evidence that methanogenesis was temporarily inhibited in particle size fractions below $840 \mu \mathrm{m}$. Variability in the $\mathrm{CH}_{4}$ production response between duplicate samples is potentially due to small differences in particle size profiles added to each bioreactor or reactor-specific variability in the microbial community's ability to convert rapidly generated hydrolysis products to $\mathrm{CH}_{4}$.

Fig. 4 gives an indication of why gas production initiates, but then lags in the smaller particle size/higher surface area size fractions. Gas composition in the reactor headspace shows increased levels of $\mathrm{CO}_{2}$ in the initial stages of degradation in the reactors where $\mathrm{CH}_{4}$ production stalls, Fig. 4a. There is also a corresponding decrease in $\mathrm{pH}$ that is more pronounced in the reactors with lower particle sizes, Fig. 4b, due to insufficient buffering capacity of the system. This decrease can be attributed to the build up of VFAs and resultant reactor acidification, which is a known reason for inhibition of $\mathrm{CH}_{4}$ production in anaerobic systems (FrankeWhittle et al., 2014; Vavilin et al., 2008). With time, the rate of $\mathrm{CH}_{4}$ generation in all reactors recovered, but this is a clear instance in which hydrolysis rate does not limit the rate of $\mathrm{CH}_{4}$ production.

In order evaluate the impact of mechanical pre-treatment, in combination with the kinetic modeling of PHBV degradation, the relationships between lag time, rate and surface area were determined by differentiating $\mathrm{CH}_{4}$ production over time (Fig. 3). A semi-log plot of SSA yielded a linear relationship with lag time, $\lambda$, and maximum rate, $R$, (Fig. 5). This logarithmic relationship is important, because while rate increases and lag time decreases with increasing surface area, there reaches a point of diminishing returns in single-stage $A D$ where the potential for reactor upsets would outweigh improvements achieved in rate and lag time. Based on the $\mathrm{CH}_{4}$ production trends, and the $\mathrm{pH}$ and gas composition profiles, this point of diminishing return occurs near the upper end of particle sizes (lower end of SSA) investigated in this study. Pommier et al. observed a similar phenomenon in studies of shredding pre-treatment of paper and cardboard (Pommier et al., 2010).

This work suggests that the particle size threshold where the rate of hydrolysis and acetogenesis exceeds that of methanogenesis is close to $0.8 \mathrm{~mm}$. Reduction of particle size below this value would have minimal positive impact on $\mathrm{CH}_{4}$ generation, with increased potential for reactor upset. While anaerobic communities could likely adapt to smaller particles and become less sensi-

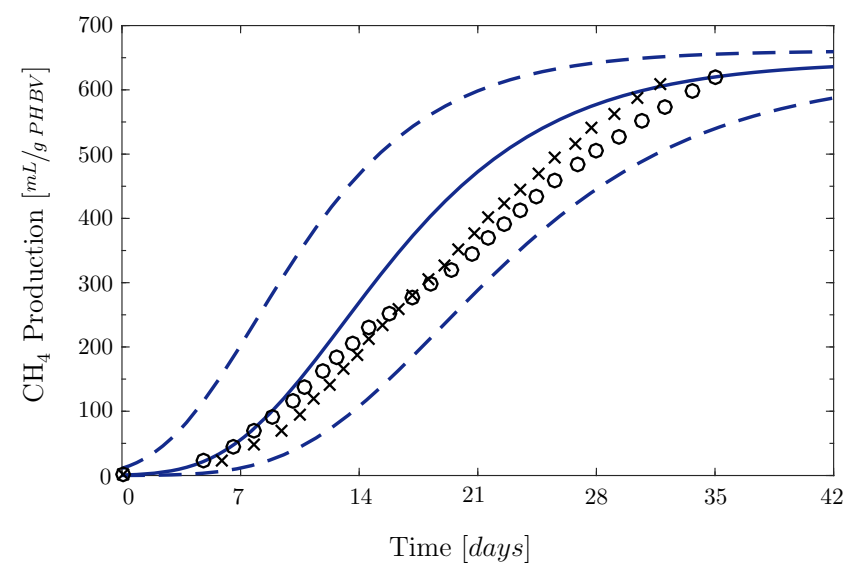

Fig. 6. Prediction (solid line) of $\mathrm{CH}_{4}$ production from $\mathrm{PHBV}$ injection molded samples (with a SA of $544 \mathrm{~mm}^{2}$ and a mass of $0.45 \mathrm{~g}$ ) obtained by combining the Gompertz and surface area model for maximum rate and lag time. The dashed maximum and minimum bands are calculated from the $95 \%$ confidence intervals of the fits from Fig. $5(R=35.4 \pm 7.7 \mathrm{~mL} / \mathrm{g} \cdot$ day and $\lambda=6.3 \pm 4.2$ days $)$ and Table 3 $\left(P_{m}=630 \pm 20 \mathrm{~mL} / \mathrm{g}\right)$.

tive to the rapid generation of hydrolysis products at small particle sizes, even continuously operated industrial digesters are sensitive to accumulation of VFAs (Franke-Whittle et al., 2014).

The maximum rate, $R$ and lag time, $\lambda$, dependence on SSA from Fig. 5 can be input into the Gompertz model and used in a predictive capacity, as shown in Fig. 6 for injection molded PHBV samples. The maximum and minimum bands in Fig. 6 are calculated from the $95 \%$ confidence intervals of the fits from Fig. 5 $(R=35.4 \pm 7.7 \mathrm{~mL} / \mathrm{g} \cdot$ day and $\lambda=6.3 \pm 4.2$ days $)$ and Table 3 $\left(P_{m}=630 \pm 20 \mathrm{~mL} / \mathrm{g}\right)$. The data for the injection molded samples fall within the combined Gompertz and surface area model prediction.

\section{Conclusions}

The Monod, Contois, and Gompertz models all provided good fits for $\mathrm{CH}_{4}$ production from anaerobic biodegradation of the bioplastic PHBV $\left(R^{2}>0.98\right)$. The Gompertz model proved particularly 
useful because it is simple, has parameters with easily interpretable physical meaning, has overall goodness of fit, and can be adapted to enable predictions by incorporating a term for surface area and particle size. A particle size breakpoint for all models was $\sim 0.8 \mathrm{~mm}$. For particles below this size, $\mathrm{CO}_{2}$ accumulated and $\mathrm{pH}$ decreased, indicating that hydrolysis was no longer ratelimiting, and a more complex model is required.

Model derivations, fits, and additional calculations are provided in detail in the supplementary information in Appendix A, along with supporting figures.

\section{Acknowledgments}

The authors thank BioProcess Control, SeaHold LLC, and Team Biogas for their generous support and collaboration with the AMPTS II. We also thank the City of San Jose and the employees of the San Jose Waste Water Treatment Plant for their assistance in obtaining inoculum for these experiments. Part of this work was performed at the Stanford Nano Shared Facilities (SNSF) and the Soft and Hybrid Materials Facility (SMF) at Stanford University. This work was funded by CalRecycle Contract No. DRRR10020, California EPA Department of Toxic Substances Control Grant No. 07T3451, NSF CMMI Grant 0900325, an unrestricted gift from Chevron, and individual graduate funding from the EPA Star Graduate Fellowship and the Stanford Civil Engineering Charles H. Leavell Graduate Fellowship.

\section{Appendix A. Supplementary data}

Supplementary data associated with this article can be found, in the online version, at http://dx.doi.org/10.1016/j.biortech.2016.11. 119.

\section{References}

American Public Health Association, American Water Works Association, Water Environment Federation, 1998. Standard Methods for the Examination of Water and Wastewater. 20th ed., American Public Health Association.

ASTM, 2002. D5526-94, 2002. Standard Test Method for Determining Anaerobic Biodegradation of Plastic Materials Under Accelerated Landfill Conditions. ASTM International.

ASTM, 2007. D5210-92, 2007. Standard Test Method for Determining the Anaerobic Biodegradation of Plastic Materials in the Presence of Municipal Sewage Sludge. ASTM International.

Boulanger, A., Pinet, E., Bouix, M., Bouchez, T., Mansour, A.A., 2012. Effect of inoculum to substrate ratio (I/S) on municipal solid waste anaerobic degradation kinetics and potential. Waste Manage. 32, 2258-2265.

Brulé, M., Oechsner, H., Jungbluth, T., 2014. Exponential model describing methane production kinetics in batch anaerobic digestion: a tool for evaluation of biochemical methane potential assays. Bioprocess Biosyst. Eng. 37, 1759-1770.

Bullock, C., Bicho, P., Zhang, Y., Saddler, J., 1996. A solid chemical oxygen demand (COD) method for determining biomass in waste waters. Water Res. 30, 12801284.

Buswell, A.M., Mueller, H.F., 1952. Mechanism of methane fermentation. Ind. Eng. Chem. 44, 550-552.
Franke-Whittle, I.H., Walter, A., Ebner, C., Insam, H., 2014. Investigation into the effect of high concentrations of volatile fatty acids in anaerobic digestion on methanogenic communities. Waste Manage. 34, 2080-2089.

Gartiser, S., Wallrabenstein, M., Stiene, G., 1998. Assessment of several test methods for the determination of the anaerobic biodegradability of polymers. J. Environ. Polym. Degr. 6, 159-173.

Ge, X., Xu, F., Li, Y., 2016. Solid-state anaerobic digestion of lignocellulosic biomass: Recent progress and perspectives. Bioresour. Technol. 205, 239-249.

Gutierrez-Wing, M.T., Stevens, B.E., Theegala, C.S., Negulescu, I.I., Rusch, K.A., 2010 Anaerobic biodegradation of polyhydroxybutyrate in municipal sewage sludge. J. Environ. Eng. 136, 709-718.

Katdare, A., Chaubal, M., 2006. Excipient Development for Pharmaceutical, Biotechnology, and Drug Delivery Systems. CRC Press.

Kenealy, W., Zeikus, J.G., 1981. Influence of corrinoid antagonists on methanogen metabolism. J. Bacteriol. 146, 133-140.

Kong, B.W., Kim, J.I., Kim, M.J., Kim, J.C., 2003. Porcine pancreatic $\boldsymbol{\alpha}$-amylase hydrolysis of native starch granules as a function of granule surface area. Biotechnol. Progr. 19, 1162-1166.

Lay, J.J., Li, Y.Y., Noike, T., 1998. Mathematical model for methane production from landfill bioreactor. J. Environ. Eng. 124, 730-736.

Liu, G., Zhang, R., El-Mashad, H.M., Dong, R., 2009. Effect of feed to inoculum ratios on biogas yields of food and green wastes. Bioresour. Technol. 100, 5103-5108.

Mezzanotte, V., Bertani, R., Innocenti, F.D., Tosin, M., 2005. Influence of inocula on the results of biodegradation tests. Polym. Degrad. Stab. 87, 51-56.

Miller, S.A., Srubar III, W.V., Billington, S.L., Lepech, M.D., 2015. Integrating durability-based service-life predictions with environmental impact assessments of natural fiber-reinforced composite materials. Resour. Conserv. Recycl. 99, 72-83.

Morse, M.C., 2010. Anaerobic Biodegradation of Biocomposites for the Building Industry. Stanford University. Ph.D. thesis.

Owen, W., Stuckey, D., Healy, J., Young, L., McCarty, P., 1979. Bioassay for monitoring biochemical methane potential and anaerobic toxicity. Water Res. 13, 485-492.

Pommier, S., Llamas, A.M., Lefebvre, X., 2010. Analysis of the outcome of shredding pretreatment on the anaerobic biodegradability of paper and cardboard materials. Bioresour. Technol. 101, 463-468.

Ryan, C.A., 2016. Sustainable Engineering of Biopolymer Composites: End-of-Life Degradation Mechanisms. Stanford University. Ph.D. thesis.

Shelton, D.R., Tiedje, J.M., 1984. General method for determining anaerobic biodegradation potential. Appl. Environ. Microbiol. 47, 850-857.

Srubar III, W.V., Pilla, S., Wright, Z.C., Ryan, C.A., Greene, J.P., Frank, C.W., Billington, S.L., 2012. Mechanisms and impact of fiber-matrix compatibilization techniques on the material characterization of PHBV/oak wood flour engineered biobased composites. Compos. Sci. Technol. 72, 708-715.

Tsui, A., Wright, Z.C., Frank, C.W., 2013. Biodegradable polyesters from renewable resources. Annu. Rev. Chem. Biomol. Eng. 4, 143-170.

Vavilin, V., Fernandez, B., Palatsi, J., Flotats, X., 2008. Hydrolysis kinetics in anaerobic degradation of particulate organic material: An overview. Waste Manage. 28, 939-951.

Vavilin, V., Lokshina, L.Y., Jokela, J., Rintala, J., 2004. Modeling solid waste decomposition. Bioresour. Technol. 94, 69-81.

Vavilin, V., Rytov, S., Lokshina, L., 1996. A description of hydrolysis kinetics in anaerobic degradation of particulate organic matter. Bioresour. Technol. 56, 229-237.

Wang, Z.W., Li, Y., 2014. A theoretical derivation of the Contois equation for kinetic modeling of the microbial degradation of insoluble substrates. Biochem. Eng. J. $82,134-138$.

Wu, W.M., Hickey, R.F., Zeikus, J.G., 1991. Characterization of metabolic performance of methanogenic granules treating brewery wastewater: role of sulfate-reducing bacteria. Appl. Environ. Microbiol. 57, 3438-3449.

Xu, F., Li, Y., Wang, Z.W., 2015. Mathematical modeling of solid-state anaerobic digestion. Prog. Energy Combust. Sci. 51, 49-66.

Yeh, A.I., Huang, Y.C., Chen, S.H., 2010. Effect of particle size on the rate of enzymatic hydrolysis of cellulose. Carbohydr. Polym. 79, 192-199.

Zwietering, M., Jongenburger, I., Rombouts, F., Van't Riet, K., 1990. Modeling of the bacterial growth curve. Appl. Environ. Microbiol. 56, 1875-1881. 